\title{
130. Intracranial Epidermoid
}

\author{
Y. Inaba, M. Takahashi, H. Negishi, Y. Matsutani, \\ T. Matsumoto and E. Misu \\ Department of Surgery, Tokyo Medicodental College
}

\section{Heterotopic Hypophysial Adenoma of the Frontal Lobe$$
\text { - Report of a Case- }
$$

\author{
Kenji Tanaka, K. Ito, T. Tsunoda and H. Nonaka \\ 2nd Dept. of Surgery, Juntendo University, School of Medicine
}

Heterotopic hypophysial adenoma is a rave disease in this country and only one case has been reported by the staffs of Mie Medical College.

We have experienced a case of heterotopic hypophysial adenoma occupied of the left frontal lobe.

The patient is 45 years old male. He complained of headache and vomiting as subjective symptoms. Lowering of impressibility and disorientation were noted as neurological findings. With these findings and with the results of examination by carotid angiography and ultrasonoechography, we diagnosed as heterotopic hypophysial adenoma of the left frontal lobe. Osteoplastic trephynation carried out for the left frontal region and picked out clearly distinguished dark red tumor from Broadmans area 9 and 10 . The size of the tumor was $5 \times 4 \times 3 \mathrm{~cm}$ and it was covered by a thin fibrous capsula.

The tumor was a malignant hypophysial adenoma by histological findings.

The postoperative course is good and there is not any sign of relapse at present.

\author{
132. Multiple Primary Intracranial Tumors Meningioma \\ Associated with Hypophyseal Tumor \\ - Report of a Case - \\ Tokuro KUNIEDA \\ Second Surgical Division, Gifu Medical School
}

Multiple primary tumor occurring intracranially is very uncommon. 